\title{
Mechanism of Iodine(III)-Promoted Oxidative Dearomatizing Hy- droxylation of Phenols: Evidence for Radical-Chain Pathway
} \author{
and Marcin Kalek*a \\ ${ }^{a}$ Centre of New Technologies, University of Warsaw, Banacha 2C, 02-097 Warsaw, Poland \\ ${ }^{\mathrm{b}}$ Faculty of Chemistry, University of Warsaw, Pasteura 1, 02-093 Warsaw, Poland \\ ${ }^{c}$ Faculty of Physics, University of Warsaw, Pasteura 5, 02-093 Warsaw, Poland
}

Karol Kraszewski ${ }^{\mathrm{a}, \mathrm{b}}$, Ireneusz Tomczyk ${ }^{\mathrm{a}, \mathrm{b}}$, Aneta Drabinska ${ }^{\mathrm{c}}$, Krzysztof Bienkowski $^{\mathrm{a}}$, Renata Solarska ${ }^{\mathrm{a}}$,

\begin{tabular}{|c|c|}
\hline (liDA & $\begin{array}{l}\text { Kinetics } \\
\text { UV } \\
\text { NMR } \\
\text { Cyclic } \\
\text { voltammetry } \\
\begin{array}{l}\text { EPR } \\
\text { Radical clocks } \\
\text { Inhibition } \\
\text { with TEMPO }\end{array}\end{array}$ \\
\hline $\begin{array}{l}\text { ABSTRACT: In the recent years, the dearor } \\
\text { induced by hypervalent iodine(III) reagents } \\
\text { experimental mechanistic studies of this imp } \\
\text { reaction remained elusive and as of today th } \\
\text { describe systematic investigations of the dear } \\
\text { Kinetics, EPR spectroscopy, and reactions w } \\
\text { are incorrect, and that the transformation in } \\
\text { the key chain-carrying intermediate. Moreov } \\
\text { voltammetry show that before reacting with } \\
\text { the iodine(III) center, causing this formally } \\
\text { identified as the rate-determining step of th } \\
\text { species, which is the second chain-carrying } r \\
\text { to rationalize all }\end{array}$ & $\begin{array}{l}\text { tization of phenols with the addition of nucleophiles to the aromatic ring, } \\
\text { id catalysts, has emerged as a highly useful synthetic approach. However, } \\
\text { tant process have been extremely scarce. As a result, the mechanism of the } \\
\text { e exist as many as three distinct mechanistic proposals. In this report, we } \\
\text { natizing hydroxylation of phenols using an array of experimental techniques. } \\
\text { radical probes demonstrate that all the previously suggested mechanisms } \\
\text { act proceeds via a radical-chain mechanism, with the aryloxyl radical being } \\
\text {, UV and NMR spectroscopy, high-resolution mass spectrometry, and cyclic } \\
\text { e aryloxyl radical, water molecule becomes activated by the interaction with } \\
\text { icleophilic substrate to act as an electrophile. The C-O bond formation is } \\
\text { reaction. This step generates the dearomatized product and an iodanyl(II) } \\
\text { ical. The radical-chain mechanism emerging from our investigations allows } \\
\text { garding the iodine(III)-promoted oxidative dearomatization of phenols. }\end{array}$ \\
\hline
\end{tabular}

\section{INTRODUCTION}

Hypervalent iodine(III)-promoted oxidative dearomatization of phenols, coupled with the addition of nucleophiles to the ortho or para position of the ring, constitutes a powerful synthetic strategy, enabling access to important molecular scaffolds (Scheme 1). ${ }^{1}$ The reaction has been accomplished in both interand intramolecular fashion with a variety of nucleophilic species, such as water, alcohols, carboxylates, amides, $\mathrm{C}-\mathrm{C}$ double bonds, electron-rich aromatic rings, and other. ${ }^{2}$ The utility of this process is further reinforced by the fact that its products are versatile synthetic intermediates, which can be directly engaged in a subsequent build-up of the molecular complexity. ${ }^{3}$ Particularly noteworthy, the reaction can be made catalytic in the iodine-containing reagent by an in situ reoxidation of the otherwise refuse iodoarene back to I(III) species, with for instance $m$-chloroperbenzoic acid. ${ }^{4}$ This provides an opportunity for the development of practical asymmetric variants of the reaction and, indeed, several such enantioselective catalytic phenol dearomatizations employing chiral iodine-containing compounds have been recently reported. ${ }^{1 \mathrm{c}-\mathrm{d}, 5}$

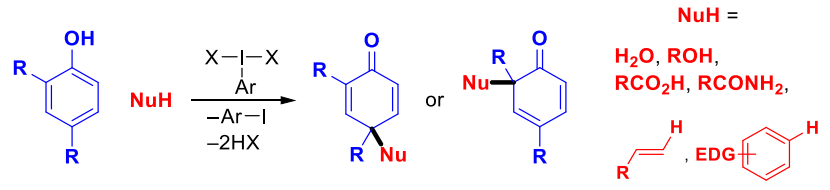

Scheme 1. Oxidative Dearomatizing Addition of Nucleophiles to Phenols Promoted by Iodine(III) reagents.

There are three distinct general mechanisms usually proposed for these phenol dearomatizations with iodine(III) reagents (Scheme 2). The most commonly invoked one assumes the incipient coordination of the phenolic oxygen to the iodine(III) center, forming intermediate A. This, due to the strongly electron-withdrawing nature of the hypervalent iodine, primes the attack of the nucleophile on the ring (pathway 1; TS1), resulting in simultaneous dearomatization and reduction of iodine. Such a mechanism has been supported by the recent computational study by Houk and Xue on the asymmetric spirolactonization, wherein it has been shown to proceed via a feasible energy barrier and to reproduce the experimentally observed enantioselectivity. ${ }^{6}$ In the second mechanistic pathway, often referred to as dissociative, intermediate $\mathbf{A}$ undergoes a unimolecular fragmentation, reducing iodine and yielding phenoxenium ion $\mathbf{B}$ 
(pathway 2; TS2). The latter subsequently reacts with the nucleophile to afford the dearomatized product. The dissociative pathway has been advocated for in a computational work by Harned on the hydroxylation of $p$-cresol using phenyliodine(III) diacetate (PIDA), however the calculated energy barrier was rather high. ${ }^{7}$ This was later followed up by a Hammett study, the only existing experimental investigation on the hypervalent iodine-promoted dearomatization of phenols, which has been also interpreted in favor of the dissociative mechanism. ${ }^{8}$ The final mechanistic alternative involves the initial electrophilic addition of the iodine atom to the phenolic ring (pathway 3 ). Resulting intermediate $\mathbf{C}$ is then attacked by the nucleophile, substituting the iodine-based leaving group in an $\mathrm{S}_{\mathrm{N}} 2$ ' fashion (TS3). According to the calculations by Ariafard, this pathway is the most energetically favorable option in the PIDA-promoted addition of methanol to $p$-cresol, but again requiring to cross a sizable barrier. ${ }^{9}$ The incorporation of iodine into the phenol ring, observed in some reactions with PIDA, also indirectly lends support to this mechanistic possibility. ${ }^{10}$
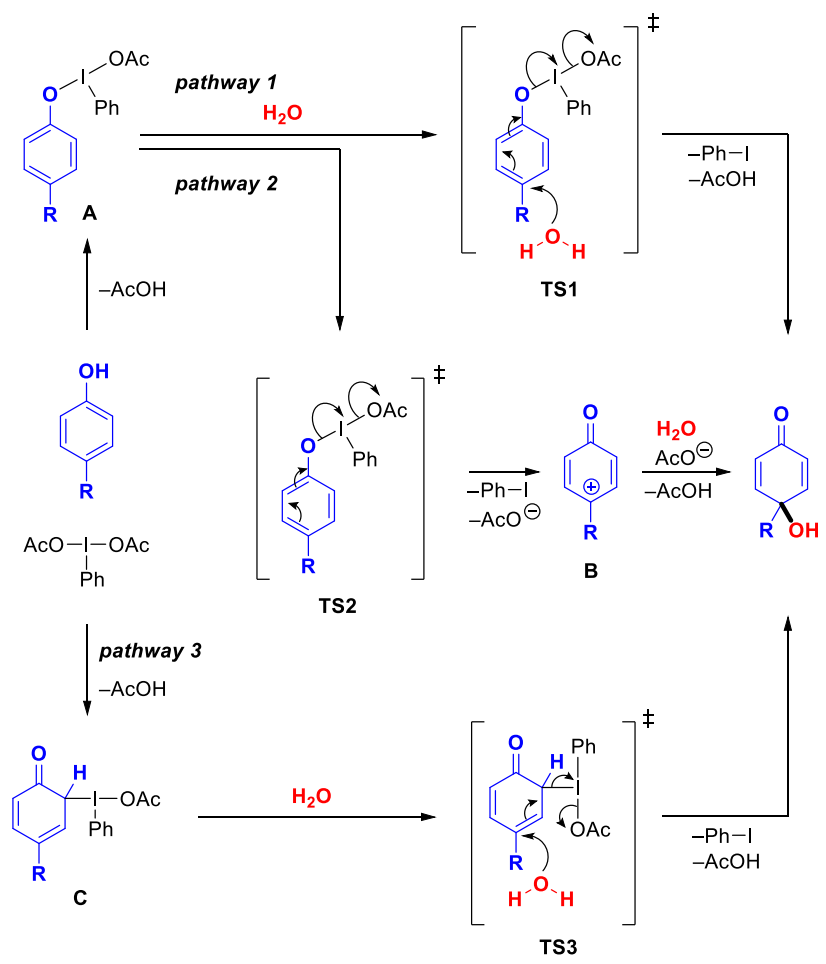

Scheme 2. General Mechanistic Pathways Proposed for the Oxidative Dearomatizing Addition of Nucleophiles to Phenols, Exemplified by a PIDA-Promoted Hydroxylation.

Interestingly, none of the mechanisms presented in Scheme 2 can fully account for all the observed characteristics of the reaction. Namely, the two associative pathways 1 and 3 do not provide explanation why the addition of a nucleophile displays a clear preference to occur at the position of the phenolic ring containing a substituent, while the other ortho or para sites are unsubstituted, thus more sterically available. They offer also wrong predictions from the electronic viewpoint, as the nucleophile addition via both TS1 and TS3 should be favored next to an electron-withdrawing group, while the Hammett plot shows a precisely opposite trend. ${ }^{8}$ On the other hand, the major flaw of the dissociative pathway 2 is that it cannot rationalize the enantioselectivity of the reactions carried out in the presence of chiral iodine(III) regents or catalysts. This is because the iodine species is not directly involved in the stereodetermining bond forming step between phenoxenium ion $\mathbf{B}$ and the nucleophile.

The present mechanistic ambiguity and the contradictory conclusions stemming from the computational studies hinder a rational design of more efficient and selective catalysts for this important reaction. In this context, we decided to undertake systematic investigations of the mechanism of the hypervalent iodine(III)-promoted oxidative dearomatization of phenols. The obtained results provide fresh and significant insights. Foremost, they strongly suggest that the reaction in fact follows a radical-chain pathway, involving a nucleophilic aryloxyl radical as the key intermediate. ${ }^{11}$ Oppositely, the formally nucleophilic substrate (NuH in Scheme 1) actually undergoes an unpolung by a coordination to the iodine(III) center and reacts as an electrophile in an single-electron transfer (SET) process. The putative radical-chain mechanism emerging from our investigations allows to encompass all the experimental observations, including the regioselectivity, the Hammet relationship, and the ability to accomplish asymmetric transformations.

\section{RESULTS AND DISCUSSION}

Kinetics. We started our investigations by examining the kinetics of a model oxidative dearomatizing hydroxylation of 2,4di-tert-butylphenol 1 promoted by PIDA in $\mathrm{MeCN} / \mathrm{H}_{2} \mathrm{O}$ mixture (Scheme 3). The reaction uniformly yields the 4-hydroxylation product $\mathbf{2}$ in high selectivity ( $>98 \%$ ), with a trace formation of the 2-hydroxylated side-product.
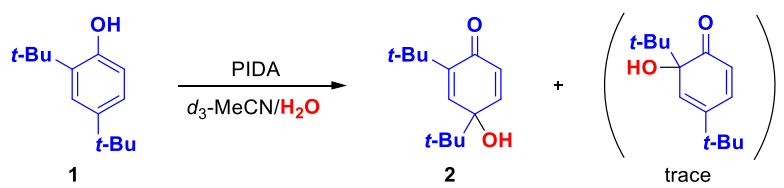

Scheme 3. A Model Oxidative Dearomatizing Hydroxylation of 2,4-di-tert-Butylphenol Promoted by PIDA.

First, the progress of the reaction was monitored over time at two different $\mathrm{H}_{2} \mathrm{O}$ contents in the reaction mixture, namely $5 \%$ and $10 \%(\mathrm{v} / \mathrm{v})$. The formation of the product is clearly faster in the latter case (Figure 1A). The analysis of the decay of the starting material 1 shows that the reaction displays an overall pseudo-first order in the concentrations of the substrates, as the linear dependences of $\mathrm{LN}\left([\mathbf{1}] /[\mathbf{1}]_{0}\right)$ vs. time were observed (Figure 1B). Interestingly, when the reaction was carried out under identical conditions, but using phenyliodine(III) bis(trifluoroacetate) (PIFA), instead of PIDA, the formation of product was virtually instantaneous (full conversion in the first NMR spectra). 

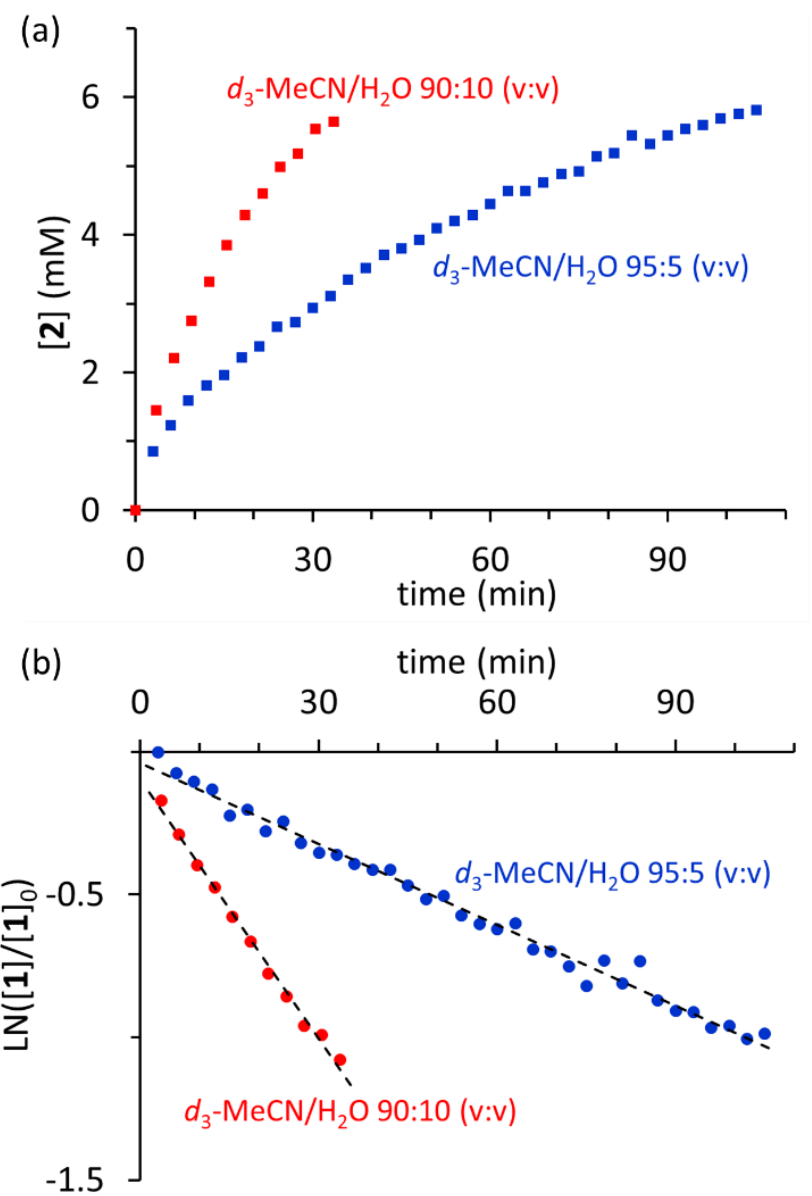

Figure 1. (A) Time-course of the reaction shown in Scheme 3 carried out in $d_{3}-\mathrm{MeCN} / \mathrm{H}_{2} \mathrm{O}$ 95:5 and 90:10 (v:v) mixtures; [1] $]_{0}=10$ $\mathrm{mM},[\mathrm{PIDA}]_{0}=10 \mathrm{mM}, 0{ }^{\circ} \mathrm{C}$; concentrations were determined by ${ }^{1} \mathrm{H}$ NMR spectroscopy relative to internal standard. (B) Plots of $\mathrm{LN}\left([\mathbf{1}] /[\mathbf{1}]_{0}\right)$ vs. time.

To ascribe the orders to the concentrations of specific reagents, we performed an initial rate study for the reaction shown in Scheme 3. The analysis of the obtained data results in an experimental rate law (1), wherein the reaction is zeroth order in the concentration of phenol 1 (Figure 2A), first order in the concentration of PIDA (Figure 2B), and second order in the concentration of $\mathrm{H}_{2} \mathrm{O}$ (Figure 2C). This is in line with the overall pseudo-first order, determined for the reactions monitored over a longer period (Figure $1 ; \mathrm{H}_{2} \mathrm{O}$ is present in a great excess, rendering its concentration constant with conversion, hence its influence on the rate does not appear in those experiments).

$$
\text { rate }=k[\mathrm{PIDA}]\left[\mathrm{H}_{2} \mathrm{O}\right]^{2}
$$

Assuming the above form of the rate law, the thermodynamic parameters of the process were determined by the means of Eyring plot (Figure 3). Notably, the reaction displays a strongly negative entropy of activation $\left(-42.4 \mathrm{cal} \cdot \mathrm{mol}^{-1} \cdot \mathrm{K}^{-1}\right)$, implying an associative character of the rate-determining events. This is in a good agreement with rate law (1) that is overall third-order, including two waters, whose involvement should be indeed associated with a large loss of entropy. The free-energy barrier at is calculated to $21.9 \pm 0.7$ and $23.0 \pm 0.9 \mathrm{kcal} \cdot \mathrm{mol}^{-1}$ at $0{ }^{\circ} \mathrm{C}$ and 25 ${ }^{\circ} \mathrm{C}$, respectively.
Finally, we established that the reactions carried out using $\mathrm{H}_{2} \mathrm{O}$ and $\mathrm{D}_{2} \mathrm{O}$ show no measurable difference in the rates (Figure $\mathrm{S} 1$ ).
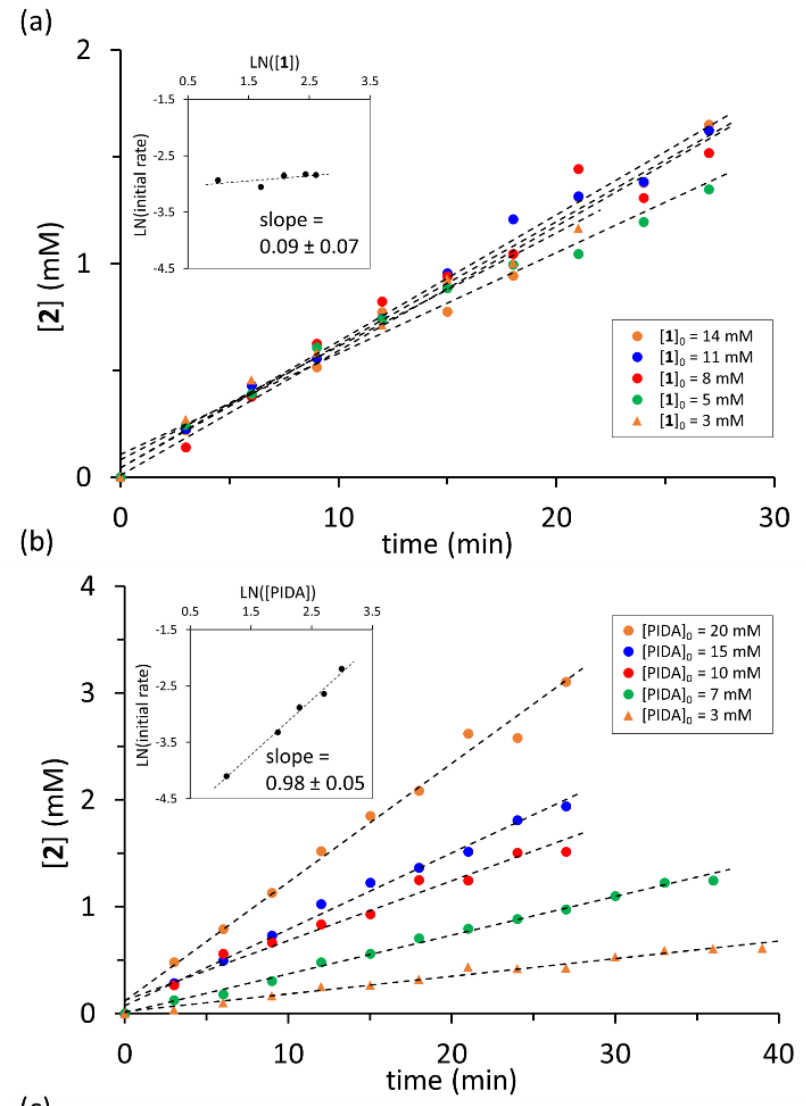

(c)

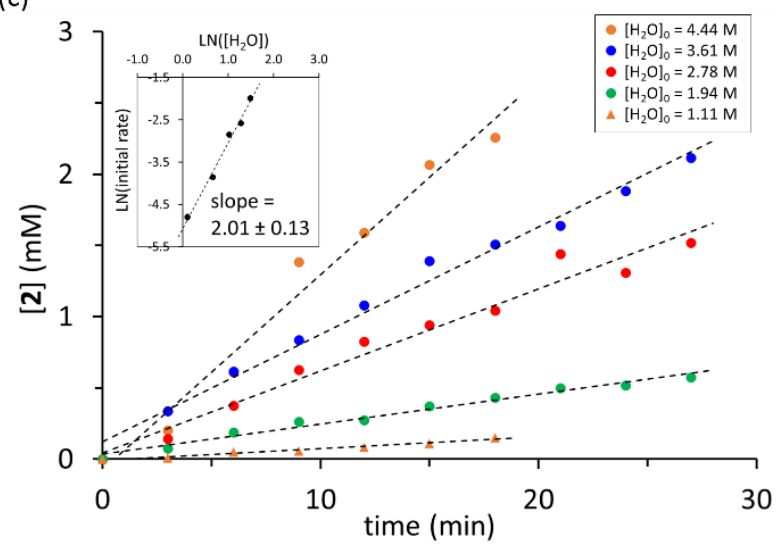

Figure 2. Initial rate measurements for the reaction shown in Scheme 3 with varied concentration of (a) 1, (b) PIDA, and (c) $\mathrm{H}_{2} \mathrm{O}$. The insets show corresponding LN-LN plots. If not otherwise stated: $[1]_{0}=10 \mathrm{mM},[\mathrm{PIDA}]_{0}=10 \mathrm{mM},\left[\mathrm{H}_{2} \mathrm{O}\right]_{0}=2.78 \mathrm{M}, 0{ }^{\circ} \mathrm{C}, d_{3}-$ $\mathrm{MeCN}$; product concentration was determined by ${ }^{1} \mathrm{H}$ NMR spectroscopy relative to internal standard. 


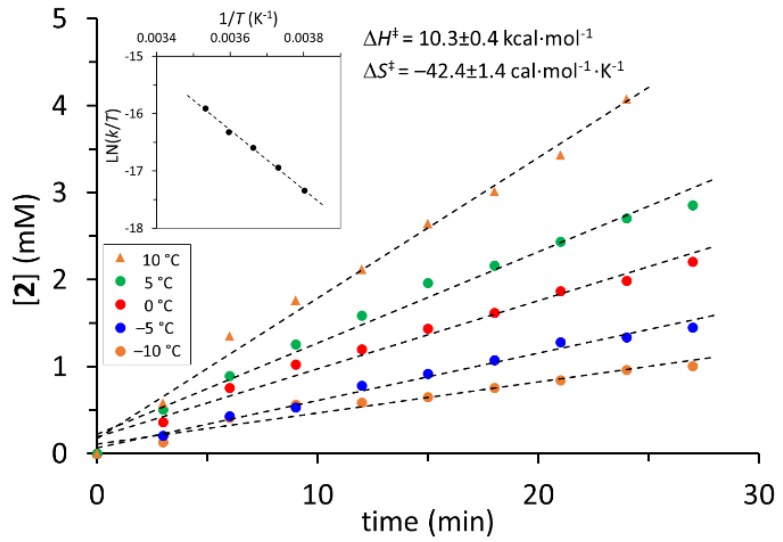

Figure 3. Temperature-dependence of the initial rate for the reaction shown in Scheme 3. The inset shows corresponding Eyring plot, assuming rate law (1); $[\mathbf{1}]_{0}=10 \mathrm{mM},[P I D A]_{0}=10 \mathrm{mM}$, $\left[\mathrm{H}_{2} \mathrm{O}\right]_{0}=2.78 \mathrm{M}, d_{3}-\mathrm{MeCN}$; product concentration was determined by ${ }^{1} \mathrm{H}$ NMR spectroscopy relative to internal standard.

Taken together, the results of above kinetic experiments demonstrate that the mechanisms depicted in Scheme 2 are all incorrect. Foremost, in all three of them phenol substrate participates prior to the respective rate-determining steps (TS1TS3), in a direct contrast with the observed absence of phenol concentration in the rate law. Additionally, the observed intriguing second order dependence of the rate on the concentration of $\mathrm{H}_{2} \mathrm{O}$ cannot be satisfactorily explained on the basis of those mechanisms. In particular, the substantial rate enhancement with the increase of water content speaks strongly against the dissociative mechanism (Scheme 2, pathway 2), in which $\mathrm{H}_{2} \mathrm{O}$ is engaged only after the rate-determining dissociation of intermediate A. This is further reinforced by the large negative entropy of activation, unlikely for a dissociative process. The measured experimental free energy barrier $\left(22-23 \mathrm{kcal} \cdot \mathrm{mol}^{-1}\right)$ is considerably lower than those determined computationally for pathways $2^{7}$ and $3^{9}$, but in agreement to that computed for pathway $1 .{ }^{6}$ However, the computational studies on the associative mechanisms have shown that in both the transition states of type TS1 and TS3 (Scheme 2, pathways 1 and 3) for the barriers to be feasible, the attack of nucleophile must proceed with a simultaneous deprotonation by an acetate anion (not shown in the scheme). ${ }^{69}$ This is, however, inconsistent with the lack of a solvent kinetic isotope effect upon the exchange of $\mathrm{H}_{2} \mathrm{O}$ for $\mathrm{D}_{2} \mathrm{O}$.

The only mechanistic possibility that we could conceive, able to encompass the observed kinetic characteristics of the reaction is a radical-chain process. Specifically, the engagement of phenol in the kinetically irrelevant step of the chain would allow to attain the observed zeroth kinetic order. This is perfectly feasible, assuming that aryloxyl radical, derived from the phenol, has the highest relative stability of all the chain-carrying radicals, so that the step which consumes it determines the overall propagation rate. Conversely, fast steps involving the other chaincarrying radicals, including the one engaging the phenol and regenerating the aryloxyl radical, would not contribute to the overall rate. To achieve the second order in the concentration of $\mathrm{H}_{2} \mathrm{O}$ and at the same time conform to the lack of solvent kinetic isotope effect, two $\mathrm{H}_{2} \mathrm{O}$ molecules would need to be involved in fast pre-equilibria within the rate-determining sequence, whose final irreversible step, however, should not include the breaking of an $\mathrm{O}-\mathrm{H}$ bond. This is also viable within the radicalchain mechanism, which is proposed and discussed below.
In the following sections we present investigations aiming at substantiating the involvement of radicals in the investigated reaction and elucidating further details of the mechanism.

EPR Spectroscopy. The possible involvement of free radicals in the mechanism of dearomatization of phenols with hypervalent iodine oxidants should not in fact be surprising. On one side, the propensity of phenols to undergo a facile singleelectron oxidation coupled with a proton transfer, is wellknown and stems from the favorable formation of resonancestabilized aryloxyl radicals. ${ }^{12}$ It constitutes the basis for the antioxidant activity of phenols employed both by Nature and in technological applications. ${ }^{13}$ Aryloxyl radicals are also intermediates in numerous reactions of biological and synthetic importance. ${ }^{14}$ On the other side, the free radical chemistry of iodine(III) species is also rich, in particular, they can serve both as the initial source of radicals and sustain the propagation of a free radical chain. ${ }^{15}$ This is due to the relative ease of formation of an iodanyl(II) radical by the cleavage of the hypervalent bond, either via homolysis or a SET from a reducing agent. Finally, the radical pathways have been explicitly proven for closely related I(III)-promoted processes engaging aryl ethers. ${ }^{16}$

To probe the presence of free radicals, we measured an electron paramagnetic resonance (EPR) spectrum of the reaction mixture for the model dearomatization depicted in Scheme 3. Due to a strong dielectric absorption of microwave radiation by $\mathrm{MeCN} / \mathrm{H}_{2} \mathrm{O}$ mixtures, acetonitrile was replaced with less polar 1,4-dioxane (the reaction also proceeds well in the latter solvent, albeit at a lower rate; see Table $S 9$ for details). The registered EPR spectrum confirms that free radicals are indeed generated under these conditions (Figure 4A). ${ }^{17}$ The analysis of the obtained signal discloses that it arises from a mixture of two radical species present in $\sim 1: 1$ ratio (Figure $4 \mathrm{C}$ ). One of them is the aryloxyl radical 3 ( $g$ factor 2.005), derived from phenol $\mathbf{1}$, as identified by the density functional theory modelling (Figure 4B). The other is an unknown radical ( $g$ factor 2.004), which does not exhibit any strong hyperfine coupling to hydrogens. Putatively, it may be some iodanyl(II) radical, similar to that generated in the recently reported electrochemical oxidation of iodoarenes (see below for a discussion on the possible identity of this species). ${ }^{18,19}$ 
a)

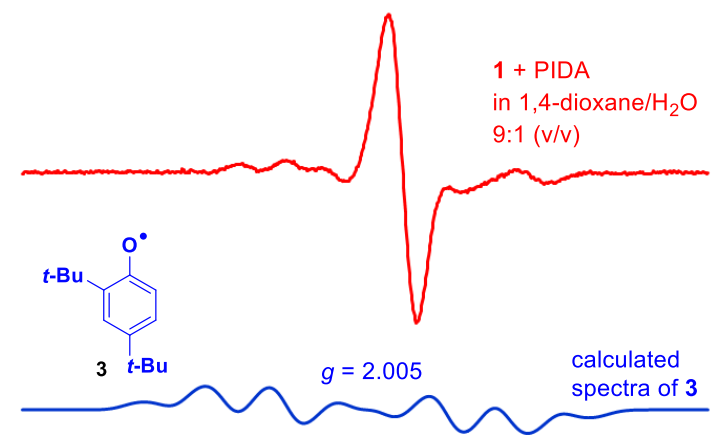

c)

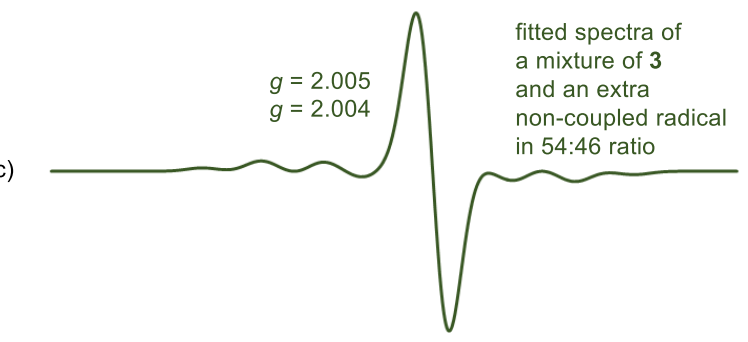

3368

$\begin{array}{rr}3378 & 3388 \\ & \text { magnetic field (G) }\end{array}$

Figure 4. (A) EPR spectrum of phenol 1 and PIDA in 1,4-dioxane $/ \mathrm{H}_{2} \mathrm{O} 9: 1(\mathrm{v} / \mathrm{v}) ;[\mathbf{1}]_{0}=100 \mathrm{mM}$, [PIDA $]_{0}=100 \mathrm{mM}, 25{ }^{\circ} \mathrm{C}$. (B) DFT-calculated spectrum of aryloxyl radical 3. (C) A simulated spectrum of a mixture of $\mathbf{3}$ and an additional non-coupled radical based on fitting to the experimental data (see the SI for details).

The formation of aryloxyl radical $\mathbf{3}$ under the reaction conditions does not yet prove that it is involved in the mechanism of the reaction and the creation of product. However, its intermediacy would provide good rationalization for the observed selectivity of the addition at the substituted ortho- or para-position of the phenolic ring, as the delocalized unpaired electron is stabilized more efficiently next to a substituent via hyperconjugation or resonance.

Reactions with Radical Clocks and Traps. To test for the actual intermediacy of aryloxyl radical in the investigated process, we have synthesized two phenols containing in-built radical clocks. ${ }^{20}$ Upon subjecting to the standard dearomatization conditions, phenol $\mathbf{4}$ having a pendant olefin, afforded exclusively a direct hydroxylation product $\mathbf{5}$, without any signs of cyclization (Scheme 4A). Such outcome may be due to the high stability of the aryloxyl radical, rendering the cyclization slow or altogether energetically disfavored. ${ }^{21}$ Conversely, the PIDApromoted hydroxylation of phenol $\mathbf{6}$, bearing a much faster 2,2dimethylcyclopropane radical clock, ${ }^{22}$ lead to the formation of compound 7 as the dominant product, with no direct hydroxylation of the phenolic ring observed (Scheme 4B). Product 7 likely origins from the sequence starting by the ring opening of the cyclopropylcarbinyl radical and a subsequent reaction of the resulting ternary radical with $\mathrm{MeCN}$. After the oxidative incorporation of oxygen, intermediate amide ${ }^{23}$ undergoes a facile intramolecular Micheal addition, restoring the aromaticity and forming the azetidine ring. Irrespective of the unusual course of the reaction with phenol $\mathbf{6}$, the characteristic opening of the cyclopropyl ring lends strong support to the involvement of aryloxyl radical in this process.

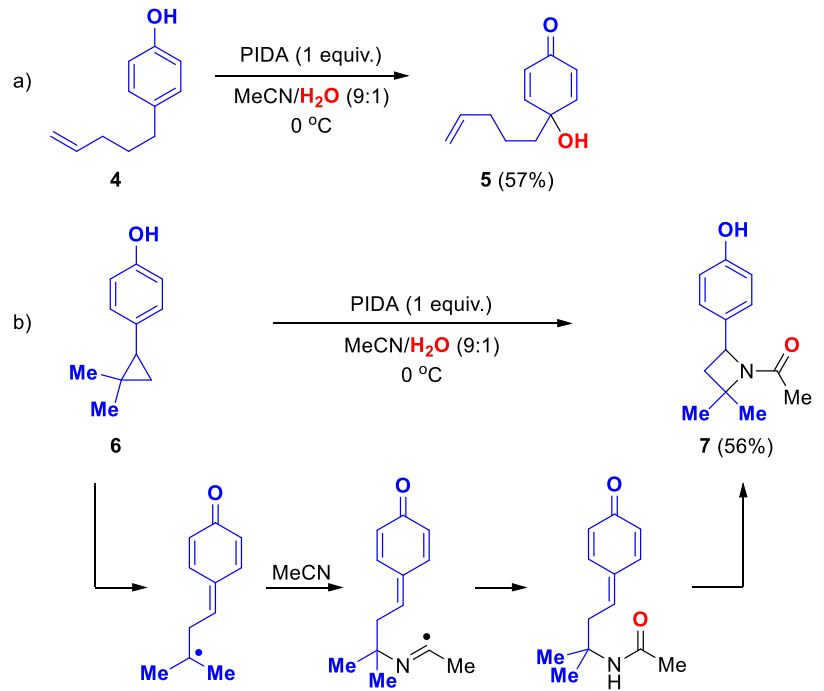

Scheme 4. PIDA-Promoted Dearomatizing Hydroxylations of Phenols Containing Radical Clocks. ${ }^{a}$

${ }^{a}$ The yields were determined in crude reactions mixtures by ${ }^{1} \mathrm{H}$ NMR spectroscopy relative to internal standard.

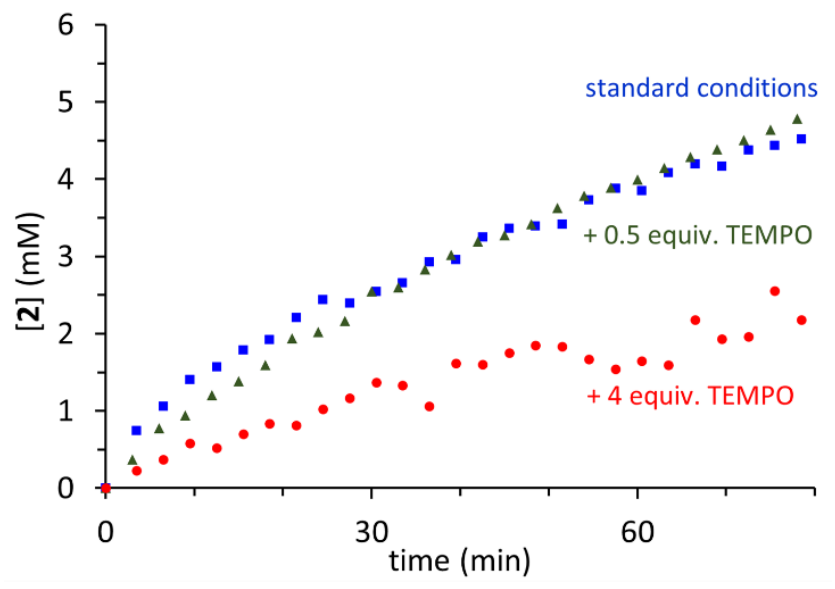

Figure 5. Time-course of the reaction shown in Scheme 3 carried out at in the absence and presence of TEMPO; $[1]_{0}=10 \mathrm{mM}$, $[\mathrm{PIDA}]_{0}=10 \mathrm{mM}, d_{3}-\mathrm{MeCN} / \mathrm{H}_{2} \mathrm{O} 9: 1(\mathrm{v} / \mathrm{v}), 0{ }^{\circ} \mathrm{C}$; product concentration was determined by ${ }^{1} \mathrm{H}$ NMR spectroscopy relative to internal standard; the fluctuations of the red data points are due to interference from TEMPO.

The iodine(III)-promoted oxidative dearomatizing additions of nucleophiles to phenols are generally quite robust and they do not usually require the exclusion of air. In particular, the reaction depicted in Scheme 3 works equally well under an inert atmosphere and when exposed to oxygen (Table S9). This should not be considered as opposing a radical mechanism, however, because although some processes involving radicals are sensitive to oxygen, other are not. The latter group often proceeds via long radical chains, which once initiated can continue unperturbed. ${ }^{24}$ We evaluated whether the reaction can be interrupted by a more potent radical trap than $\mathrm{O}_{2}$, namely 2,2,5,5-tetramethylpiperidin-1-oxyl (TEMPO). It was found that substoichiometric amounts of TEMPO do not impact the rate of the reaction, and as much as 4 equiv. are required to slow down the dearomatization by $\sim 2$-fold (Figure 5 ). While the inhibitory effect of TEMPO is only moderate, probably due to the 
large steric hindrance of aryloxyl radical $3,{ }^{25}$ it strongly points to the radical mechanism of the transformation.

UV Spectroscopy, NMR, and HRMS Studies on the Interaction of PIDA and $\mathrm{H}_{2} \mathrm{O}$ in MeCN. Having established that aryloxyl radical is implicated in the mechanism of the investigated reaction, we pursued to gain additional insight into how the bond between the ring and the nucleophile is formed. Unlike phenoxenium ion (B in Scheme 2), aryloxyl radical will not directly react with $\mathrm{H}_{2} \mathrm{O}$ providing the final product, as such step is deemed energetically disfavored due to the generation of a hydrogen atom $(\mathrm{H} \cdot)$. Therefore, we conjecture that $\mathrm{H}_{2} \mathrm{O}$ needs to undergo a prior activation, presumably by PIDA, as implied by rate law (1). The necessity for the nucleophile to interact with the hypervalent iodine species to become capable of reacting with aryloxyl radical would explain the asymmetric induction rendered by chiral hypervalent iodine reagents.

The interaction of iodine(III) compounds with nucleophilic species, such as $\mathrm{H}_{2} \mathrm{O}$ and $\mathrm{MeOH}$, has been a subject of some investigations. ${ }^{26}$ It has been for instance determined that in an aqueous solution, $\mathrm{PhI}(\mathrm{OTs}) \mathrm{OH}$ (Koser's reagent) is completely transformed into an equilibrium mixture of fully dissociated $\left[\mathrm{PhI}\left(\mathrm{OH}_{2}\right) \mathrm{OH}\right]^{+}$and $\left[\mathrm{Ph}(\mathrm{HO}) \mathrm{I}-\mathrm{O}-\mathrm{I}\left(\mathrm{OH}_{2}\right) \mathrm{Ph}\right]^{+}$ions. ${ }^{27} \mathrm{~A}$ highresolution mass spectrometry (HRMS) study of the solution of PIDA in $\mathrm{MeCN} / \mathrm{H}_{2} \mathrm{O}$ mixture has also qualitatively demonstrated the existence of analogous species. ${ }^{28} \mathrm{We}$ set out to more thoroughly investigate the behavior of PIDA when exposed to $\mathrm{H}_{2} \mathrm{O}$ under the conditions relevant to the oxidative dearomatizing hydroxylation of phenols.

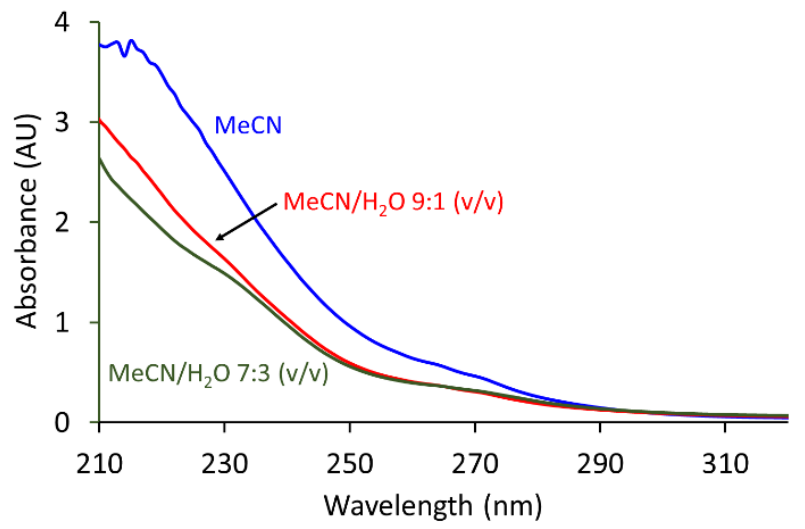

Figure 6. UV spectra of PIDA in pure $\mathrm{MeCN}$ and $\mathrm{MeCN} / \mathrm{H}_{2} \mathrm{O}$ mixtures; [PIDA] $=0.2 \mathrm{mM}$.

First, we looked for an indication of any interaction between PIDA and $\mathrm{H}_{2} \mathrm{O}$ using UV spectroscopy. The UV spectrum of the solution of PIDA in MeCN indeed undergoes an evident alteration in the presence of $\mathrm{H}_{2} \mathrm{O}$ (Figure 6).
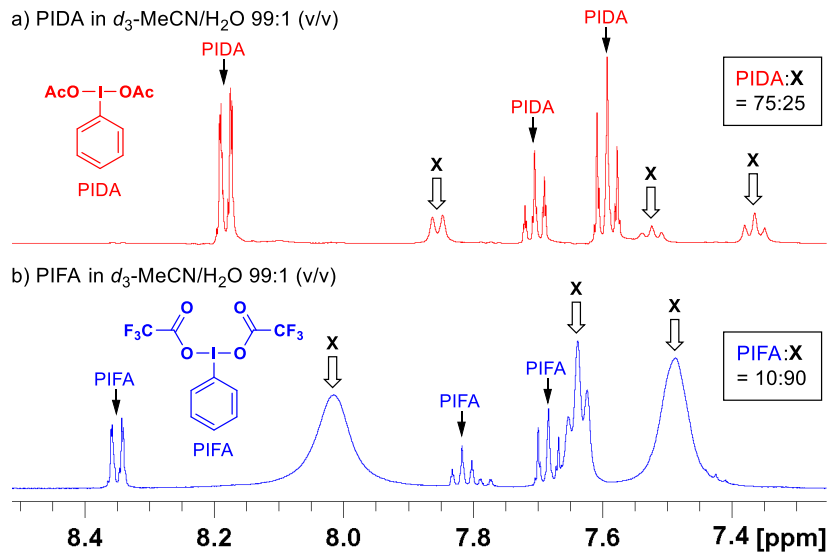

Figure 7. $500 \mathrm{MHz}{ }^{1} \mathrm{H}$ NMR spectra of (a) PIDA and (b) PIFA in $d_{3}-\mathrm{MeCN} / \mathrm{H}_{2} \mathrm{O}$ 99:1 (v/v) mixture; [PIDA/PIFA] $=50 \mathrm{mM}$. New signals appearing in the presence of $\mathrm{H}_{2} \mathrm{O}$ are indicated with $\mathbf{X}$.

To establish what the origins of the observed changes in the UV absorption pattern of PIDA are, we turned to nuclear magnetic resonance (NMR) spectroscopy. The ${ }^{1} \mathrm{H}$ NMR spectra of PIDA in $d_{3}-\mathrm{MeCN}$ contains a set of 3 aromatic protons peaks at 8.18, 7.71, and $7.59 \mathrm{ppm}$. Upon the addition of $\mathrm{H}_{2} \mathrm{O}$, a new set of somewhat broad signals of aromatic protons emerges (Figure 7A, indicated with $\mathbf{X}$ ). The novel NMR peaks are more shielded compared to those of PIDA, but they are still considerably downfield, indicating the presence of an I(III) substituent in the ring. In the case of PIFA, a similar phenomenon was also observed, however, the new NMR signals are much broader and the quantity of the corresponding species is considerably higher, as much as $90 \%$ in $d_{3}-\mathrm{MeCN} / \mathrm{H}_{2} \mathrm{O}$ 99:1 (v/v) mixture (Figure 7B). This correlates with the very high rate of phenol dearomatization promoted by PIFA (see above).

In the HRMS spectra of the solution of PIDA in $\mathrm{MeCN} / \mathrm{H}_{2} \mathrm{O}$ 9:1 (v:v) mixture, the major species are $[\mathrm{PhIOH}]^{+}(220.9456)$ and $[\mathrm{Ph}(\mathrm{HO}) \mathrm{I}-\mathrm{O}-\mathrm{IPh}]^{+}(440.8846)$, in line with the previous report. ${ }^{28}$ The only peak from acetate-containing species detected is a small $[\mathrm{Ph}(\mathrm{AcO}) \mathrm{I}-\mathrm{O}-\mathrm{IPh}]^{+}(482.8945)$ signal. In the corresponding solution of PIFA, just the former two ions are detected.

Collectively, above results show that under typical conditions employed in the oxidative dearomatizing hydroxylation of phenols, a considerable fraction of the hypervalent iodine reagent is converted into species containing $\mathrm{HO}-\mathrm{I}^{\mathrm{III}}$ and $\mathrm{I}^{\mathrm{III}}-\mathrm{O}-\mathrm{I}^{\mathrm{III}}$ moieties. These constitute the activated forms of $\mathrm{H}_{2} \mathrm{O}$, possessing an oxidative ability and exhibiting an electrophilic character at the oxygen atom, due to the direct bonding to a highly electronpoor iodine(III) center. As such, they should be prone for a single electron transfer coupling reaction with the nucleophilic aryloxyl radical, forming the alcohol product and generating an iodanyl(II) radical.

Electrochemical Properties of $\mathbf{I}(\mathrm{III})-\mathrm{H}_{2} \mathrm{O}$ Adducts. As the final part of our investigations, using cyclic voltammetry, we studied the oxidizing ability of the I(III)- $\mathrm{H}_{2} \mathrm{O}$ adducts, whose formation was described in the previous section.

First, as a reference, the reduction of PIDA was recorded voltammetrically at a glassy carbon electrode in $\mathrm{MeCN}$, in the presence of ferrocene $(\mathrm{Fc})$ as an internal redox standard (Figure $8 \mathrm{~A})$. The registered voltammogram displays two irreversible reduction waves. The first one occurs at the peak potential of - 
$1.34 \mathrm{~V}$ relative to $\mathrm{Fc} / \mathrm{Fc}^{+}$, in a full agreement with the previously reported value. ${ }^{16 \mathrm{~b}}$

(a) PIDA + ferrocene in MeCN

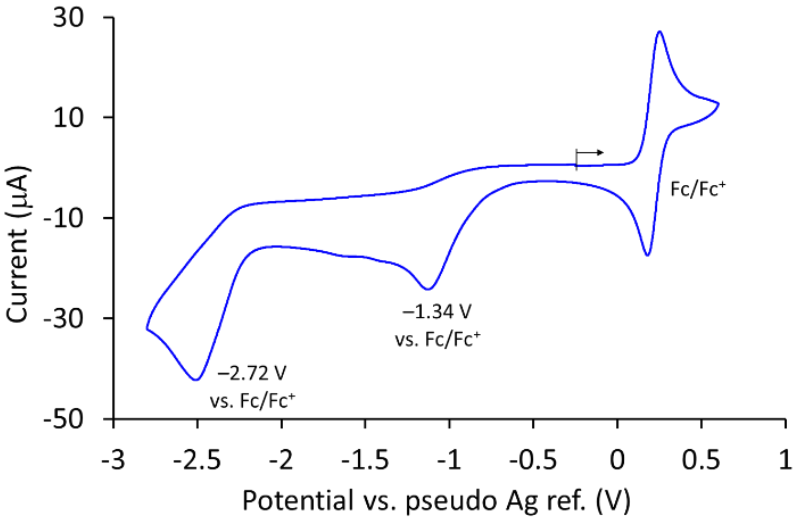

(b) PIDA in $\mathrm{MeCN} / \mathrm{H}_{2} \mathrm{O} 9: 1(\mathrm{v} / \mathrm{v})$

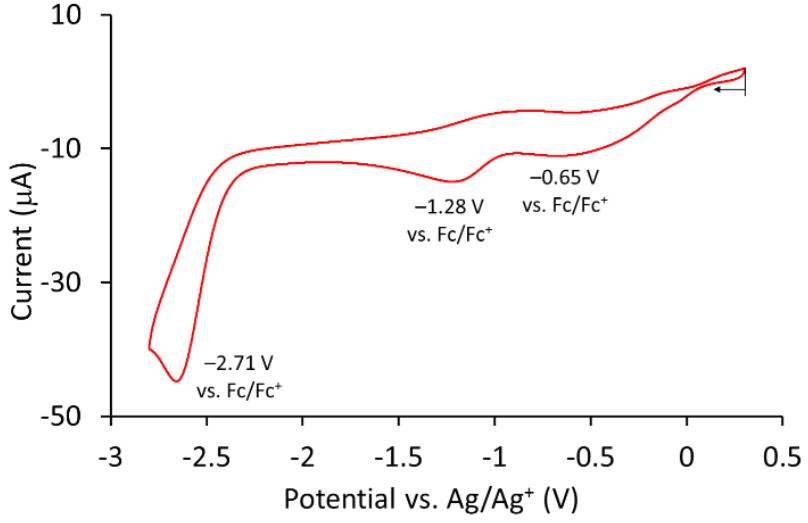

Figure 8. Voltammograms of (a) PIDA and ferrocene in $\mathrm{MeCN}$ and (b) PIDA in $\mathrm{MeCN} / \mathrm{H}_{2} \mathrm{O}$ 9:1 (v:v) mixture; [PIDA] $=1 \mathrm{mM}$, [ferrocene $]=1 \mathrm{mM},\left[n-\mathrm{Bu}_{4} \mathrm{NPF}_{6}\right]=0.1 \mathrm{M}$, scan rate $=0.1 \mathrm{~V} \cdot \mathrm{s}^{-1}$, glassy carbon electrode (radius $=1.5 \mathrm{~mm}$ ). In (a) ferrocene was used as an internal redox reference potential. In (b) a $\mathrm{Ag} / \mathrm{AgPF}_{6}$ reference electrode $\left(E_{\text {ferrocene }}=0.05 \mathrm{~V}\right.$ vs. $\mathrm{Ag} / \mathrm{Ag}^{+}$, measured separately in $\mathrm{MeCN} / \mathrm{H}_{2} \mathrm{O}$ 9:1 (v:v)) was used due to a reaction between ferrocene and PIDA. Voltammetric starting potential and initial scan direction are indicated with black arrows.

We then performed a similar measurement for the solution of PIDA in $\mathrm{MeCN} / \mathrm{H}_{2} \mathrm{O}$ 9:1 (v:v) mixture, wherein the species of interest are being present. In this case, the direct application of $\mathrm{Fc} / \mathrm{Fc}^{+}$internal redox standard turned out to be impossible, because in this solvent mixture the iodine(III) oxidants reacted with ferrocene, as noticeable by the change of the solution color. This is a very similar behavior to that reported previously by Compton and co-workers, in the case of PIDA solution in 1,1,1,3,3,3-hexafluoroisopropanol (HFIP). ${ }^{16 \mathrm{~b}}$ Following the procedure applied in the above work, the voltammetry was thus recorded against a silver/silver hexafluorophosphate reference electrode, without ferrocene. In a separate measurement, the redox potential of ferrocene was determined to be $0.05 \mathrm{vs}$. $\mathrm{Ag} / \mathrm{Ag}^{+}$ (Figure S4), allowing for referencing the data obtained in both solvents. The recorded voltammogram contains three irreversible reduction waves (Figure 8B). The first one is broad and it occurs at the peak potential of $-0.65 \mathrm{~V}$ relative to $\mathrm{Fc} / \mathrm{Fc}^{+}$. The other two waves most likely originate from the sequential reduction of PIDA, as they display peak potentials analogous to those in Figure 8A. ${ }^{29}$
The electrochemical characteristics of the solution of PIDA in $\mathrm{MeCN} / \mathrm{H}_{2} \mathrm{O}$ mixture demonstrates that it contains species that are considerably stronger oxidants than PIDA itself (by more than $0.6 \mathrm{~V})$. The superior oxidizing ability of the I(III)-H2O adducts compared to PIDA provides rationalization for the selective transfer of the $\mathrm{OH}$ group to the aryloxyl radical, furnishing the hydroxylation product, while its acetoxylated analog is not formed under the conditions shown in Scheme 3. ${ }^{30}$

Overall mechanism. The results of the experiments presented in the previous sections suggest that the iodine(III)promoted oxidative dearomatizing hydroxylation of phenols follows a radical-chain mechanism, summarized in Scheme 5.

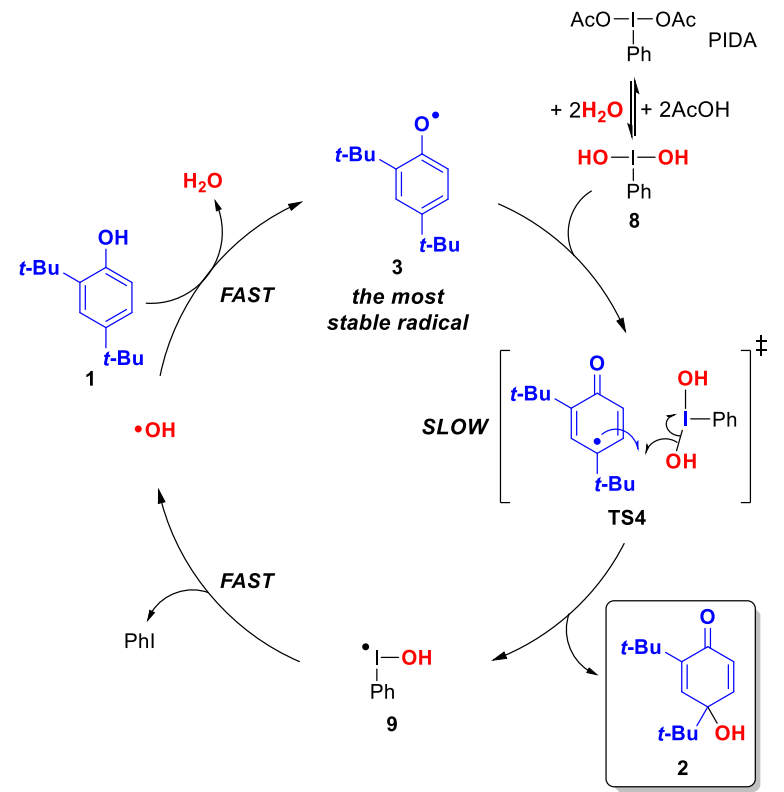

Scheme 5. Putative Radical-Chain Mechanism for the Dearomatizing Hydroxylation of 2,4-Di-tert-butylphenol 1 Promoted by PIDA.

Aryloxyl radical $\mathbf{3}$ is the key chain-carrying intermediate, which due to its high stability will be the dominant radical species present in the reaction mixture. A single-electron oxidation of 3 by an I(III)- $\mathrm{H}_{2} \mathrm{O}$ adduct (the strongest oxidant present in the reaction mixture), coupled with the $\mathrm{OH}$-transfer, yields product 2 and generates a iodanyl(II) radical. Owing to the stability of $\mathbf{3}$, this step is slow and, thus, it determines the overall rate of the reaction. Based on rate law (1), we propose that the actual oxidant is phenyliodine(III) dihydroxide $\mathbf{8}$, however, it may possibly be another related III-O species. Importantly, in putative TS4, the $\mathrm{O}-\mathrm{H}$ bond is not being broken, hence there will be no KIE upon exchanging $\mathrm{H}$ to $\mathrm{D}$, in line with the experimental findings. ${ }^{31}$

Iodanyl(II) radical (9 or a related species) is moderately stable and it is most likely the second radical detected by the EPR (Figure 4). Its fragmentation leads to $\mathrm{PhI}$ and a hydroxyl radical, which is quenched by the phenol, regenerating 3 . The overall transformation of $\mathbf{9}$ to $\mathbf{3}$ is fast, thus, the concentration of phenol 1 does not enter the rate law. ${ }^{32}$

Here it is important to remark that Scheme 5 presents only the propagation steps of the radical chain. With the current data, we are not able to establish the specific course of initiation and 
termination steps, i.e. how the radicals are created and how they fade. These aspects of the mechanism are yet to be elucidated.

Nonetheless, the mechanistic picture depicted in Scheme 5 is able to accommodate all the reported characteristics of the iodine(III)-promoted dearomatization of phenols. First, it explains the regionselectivity of the reaction - the addition will take place preferentially next to a substituent providing the highest stabilization of the delocalized unpaired electron in the aryloxyl radical, overrunning the steric factors. Secondly, the umpolung of the nucleophile, by the association with the I(III) center, renders electron-rich phenols more reactive, rationalizing the negative slope of the Hammet plot. ${ }^{8}$ Finally, the requirement for the nucleophile to be activated by the I(III) reagent during the reaction with the aryloxyl radical allows for the enantioselective formation of the product, in the case when a chiral hypervalent iodine reagent or catalyst is applied.

\section{CONCLUSIONS}

In summary, the mechanism of iodine(III)-promoted oxidative dearomatizing hydroxylation of phenols was investigated by an array of experimental techniques. Obtained results disprove the previously proposed pathways and they strongly point to the radical-chain mechanism. Specifically, it was determined that the phenol substrate is converted into the corresponding aryloxyl radical, which constitutes the key chain-carrying intermediate. In turn, the nucleophilic coupling partner needs to become activated by the coordination to the I(III) center in order to react with the aryloxyl radical, to generate the product together with a iodanyl(II) radical that further propagates the chain. The radical-chain mechanism, as the only one, is able to rationalize all the features of the reaction. This conclusion is also in a good agreement with the known propensity of both phenols and hypervalent iodine(III) regents to undergo singleelectron redox processes. Computational studies aimed at elucidating further details of the radical pathway are currently underway.

We are convinced that the established mechanism is valid for the iodine(III)-promoted oxidative dearomatizing hydroxylation and, with a high degree of confidence, alkoxylation of phenols. As far as the other dearomatizations of phenols, such as the spirolactionization, are concerned, we believe that further experimental studies are needed to draw definite conclusions. Nevertheless, the presented results provide important new insights and a framework for understanding and improving the iodine(III)-mediated reactions involving phenols. They carry also major implications for the design of novel processes employing hypervalent iodine reagents and catalysts, including asymmetric ones.

\section{SUPPORTING INFORMATION}

Experimental procedures, comparison of reactions with $\mathrm{H}_{2} \mathrm{O}$ and $\mathrm{D}_{2} \mathrm{O}$, reactions under different conditions, details of EPR simulations and EPR spectra in other solvents, cyclic voltammetry of ferrocene in $\mathrm{MeCN} / \mathrm{H} 2 \mathrm{O}$ 9:1 (v/v) mixture against $\mathrm{Ag} / \mathrm{Ag}^{+}$.

\section{Notes}

The authors declare no competing financial interest.

\section{ACKNOWLEDGMENT}

We acknowledge the financial support from the National Science Centre, Poland (2016/22/E/ST5/00566). We thank the Faculty of
Physics of the University of Warsaw for the access to NMR spectrometer. Computer time was generously provided by the Interdisciplinary Centre for Mathematical and Computational Modelling of the University of Warsaw (G75-0).

\section{REFERENCES}

(1) (a) Pouységu, L.; Deffieux, D.; Quideau, S. Hypervalent Iodine-Mediated Phenol Dearomatization in Natural Product Synthesis. Tetrahedron 2010, 66, 2235-2261; (b) Roche, S. P.; Porco, J. A. Dearomatization Strategies in the Synthesis of Complex Natural Products. Angew. Chem. Int. Ed. 2011, 50, 4068-4093; (c) Sun, W.; Li, G.; Hong, L.; Wang, R. Asymmetric Dearomatization of Phenols. Org. Biomol. Chem. 2016, 14, 2164-2176; (d) Wu, W.-T.; Zhang, L.; You, S.L. Catalytic Asymmetric Dearomatization (CADA) Reactions of Phenol and Aniline Derivatives. Chem. Soc. Rev. 2016, 45, 1570-1580.

(2) Reviews: (a) Pelter, A.; Ward, R. S. Two-Electron Phenolic Oxidations Using Phenyliodonium Dicarboxylates. Tetrahedron 2001, 57, 273-282; (b) Liang, H.; Ciufolini, M. A. Synthetic Aspects of the Oxidative Amidation of Phenols. Tetrahedron 2010, 66, 5884-5892; selected examples: (c) Wang, S.; Gates, B. D.; Swenton, J. S. A Convergent Route to Dihydrobenzofuran Neolignans via a Formal 1,3-Cycloaddition to Oxidized Phenols. J. Org. Chem. 1991, 56, 1979-1981; (d) Quideau, S.; Looney, M. A.; Pouységu, L. Oxidized Arenol Intermediates in Intermolecular Carbon-Carbon Bond Formation. Naphthoid Cyclohexa-2,4-dienones via Oxidative Nucleophilic Substitution. Org. Lett. 1999, 1, 1651-1654; (e) Pettus, L. H.; Van De Water, R. W.; Pettus, T. R. R. Synthesis of ( \pm -Epoxysorbicillinol Using a Novel Cyclohexa-2,5-dienone with Synthetic Applications to Other Sorbicillin Derivatives. Org. Lett. 2001, 3, 905-908; (f) Canesi, S.; Bouchu, D.; Ciufolini, M. A. Nitrogenous Educts through Oxidative Amidation of Phenols: The Bimolecular Reaction. Org. Lett. 2005, 7, 175-177; (g) Marsini, M. A.; Huang, Y.; Van De Water, R. W.; Pettus, T. R. R. Synthesis of Resorcinol Derived Spironitronates. Org. Lett. 2007, 9, 32293232; (h) Pouységu, L.; Chassaing, S.; Dejugnac, D.; Lamidey, A.-M.; Miqueu, K.; Sotiropoulos, J.-M.; Quideau, S. Highly Diastereoselective Synthesis of Orthoquinone Monoketals through $\lambda 3$-Iodane-Mediated Oxidative Dearomatization of Phenols. Angew. Chem. Int. Ed. 2008, 47, 3552-3555; (i) Beaulieu, M.-A.; Sabot, C.; Achache, N.; Guérard, K. C.; Canesi, S. An Oxidative Prins-Pinacol Tandem Process and Its Application to the Synthesis of (-)-Platensimycin. Chem. Eur. J. 2010, 16, 11224-11228; (j) Flyer, A. N.; Si, C.; Myers, A. G. Synthesis of Cortistatins A, J, K and L. Nat. Chem. 2010, 2, 886-892; (k) Wood, J. L.; Graeber, J. K.; Njardarson, J. T. Application of Phenolic Oxidation Chemistry in Aynthesis: Preparation of the BCE Ring System of Ryanodine. Tetrahedron 2003, 59, 8855-8858; (1) Baxendale, I. R.; Deeley, J.; Griffiths-Jones, C. M.; Ley, S. V.; Saaby, S.; Tranmer, G. K. A Flow Process for the Multi-Step Synthesis of the Alkaloid Natural Product Oxomaritidine: a New Paradigm for Molecular Assembly. Chem. Commun. 2006, 2566-2568; (m) Zheng, C.; Wang, L.; Li, J.; Wang, L.; Wang, D. Z. Ortho-Dearomatization of Phenols Creating All-Carbon Spiro-Bicycles. Org. Lett. 2013, 15, 4046-4049.

(3) (a) Burgett, A. W. G.; Li, Q.; Wei, Q.; Harran, P. G. A Concise and Flexible Total Synthesis of (-)-Diazonamide A. Angew. Chem. Int. Ed. 2003, 42, 4961-4966; (b) Wipf, P.; Spencer, S. R. Asymmetric Total Syntheses of Tuberostemonine, Didehydrotuberostemonine, and 13-Epituberostemonine. J. Am. Chem. Soc. 2005, 127, 225-235; (c) Cook, S. P.; Polara, A.; Danishefsky, S. J. The Total Synthesis of ( \pm )11-O-Debenzoyltashironin. J. Am. Chem. Soc. 2006, 128, 1644016441; (d) Vo, N. T.; Pace, R. D. M.; O'Har, F.; Gaunt, M. J. An Enantioselective Organocatalytic Oxidative Dearomatization Strategy. $J$. Am. Chem. Soc. 2008, 130, 404-405; (e) Frie, J. L.; Jeffrey, C. S.; Sorensen, E. J. A Hypervalent Iodine-Induced Double Annulation Enables a Concise Synthesis of the Pentacyclic Core Structure of the Cortistatins. Org. Lett. 2009, 11, 5394-5397; (f) Liang, H.; Ciufolini, M. A. Tandem Phenolic Oxidative Amidation-Intramolecular Diels-Alder Reaction: an Approach to the Himandrine Core. Org. Lett. 2010, 12, 1760-1763; (g) Tissot, M.; Phipps, R. J.; Lucas, C.; Leon, R. M.; Pace, R. D. M.; Ngouansavanh, T.; Gaunt, M. J. Gram-Scale Enantioselective Formal Synthesis of Morphine Through an Ortho-Para Oxidative Phenolic Coupling Strategy. Angew. Chem. Int. Ed. 2014, 53, 
13498-13501; (h) Reddy, R. R.; Gudup, S. S.; Ghorai, P. Organocatalytic, Enantioselective Synthesis of Cyclohexadienone Containing Hindered Spirocyclic Ethers through an Oxidative Dearomatization/OxaMichael Addition Sequence. Angew. Chem. Int. Ed. 2016, 55, 1511515119; (i) Williamson, A. E.; Ngouansavanh, T.; Pace, R. D. M.; Allen, A. E.; Cuthbertson, J. D.; Gaunt, M. J. Rapid Generation of Complex Molecular Architectures by a Catalytic Enantioselective Dearomatization Strategy. Synlett 2016, 27, 116-120; (j) Coffinier, R.; Assal, M. E.; Peixoto, P. A.; Bosset, C.; Miqueu, K.; Sotiropoulos, J.-M.; Pouységu, L.; Quideau, S. Total Synthesis of (-)-Bacchopetiolone via an Asymmetric Hydroxylative Phenol Dearomatization/[4+2]-Dimerization Cascade Promoted by a Novel Salen-Type Chiral Iodane. Org. Lett. 2016, 18, 1120-1123; (k) Rubush, D. M.; Morges, M. A.; Rose, B. J.; Thamm, D. H.; Rovis, T. An Asymmetric Synthesis of 1,2,4-Trioxane Anticancer Agents via Desymmetrization of Peroxyquinols through a Brønsted Acid Catalysis Cascade. J. Am. Chem. Soc. 2012, 134, 13554 13557.

(4) (a) Dohi, T.; Maruyama, A.; Yoshimura, M.; Morimoto, K.; Tohma, H.; Kita, Y. Versatile Hypervalent-Iodine(III)-Catalyzed Oxidations with $m$-Chloroperbenzoic Acid as a Cooxidant. Angew. Chem. Int. Ed. 2005, 44, 6193-6196; (b) Richardson, R. D.; Wirth, T. Hypervalent Iodine Goes Catalytic. Angew. Chem. Int. Ed. 2006, 45, 44024404; (c) Dohi, T.; Minamitsuji, Y.; Maruyama, A.; Hirose, S.; Kita, Y. A New $\mathrm{H}_{2} \mathrm{O}_{2} /$ Acid Anhydride System for the Iodoarene-Catalyzed C-C Bond-Forming Reactions of Phenols. Org. Lett. 2008, 10, 35593562; (d) Dohi, T.; Kita, Y. Hypervalent Iodine Reagents as a New Entrance to Organocatalysts. Chem. Commun. 2009, 2073-2085.

(5) Reviews: (a) Ngatimin, M.; Lupton, D. W. The Discovery of Catalytic Enantioselective Polyvalent Iodine Mediated Reactions. Aust. J. Chem. 2010, 63, 653-658; (b) Parra, A.; Reboredo, S. Chiral Hypervalent Iodine Reagents: Synthesis and Reactivity. Chem. Eur. J. 2013, 19, 17244-17260; (c) Harned, A. M. Asymmetric Oxidative Dearomatizations Promoted by Hypervalent Iodine(III) Reagents: an Opportunity for Rational Catalyst Design? Tetrahedron Lett. 2014, 55 , 4681-4689; (d) Berthiol, F. Reagent and Catalyst Design for Asymmetric Hypervalent Iodine Oxidations. Synthesis 2015, 47, 587-603; selected examples: (e) Dohi, T.; Maruyama, A.; Takenaga, N.; Senami, K.; Minamitsuji, Y.; Fujioka, H.; Caemmerer, S. B.; Kita, Y. A Chiral Hypervalent Iodine(III) Reagent for Enantioselective Dearomatization of Phenols. Angew. Chem. Int. Ed. 2008, 47, 3787-3790; (f) Quideau, S.; Lyvinec, G.; Marguerit, M.; Bathany, K.; Ozanne-Beaudenon, A.; Buffeteau, T.; Cavagnat, D.; Chénedé, A. Asymmetric Hydroxylative Phenol Dearomatization through In Situ Generation of Iodanes from Chiral Iodoarenes and m-CPBA. Angew. Chem. Int. Ed. 2009, 48 , 4605-4609; (g) Uyanik, M.; Yasui, T.; Ishihara, K. Enantioselective Kita Oxidative Spirolactonization Catalyzed by In Situ Generated Chiral Hypervalent Iodine(III) Species. Angew. Chem. Int. Ed. 2010, 49, 2175-2177; (h) Dohi, T.; Takenaga, N.; Nakae, T.; Toyoda, Y.; Yamasaki, M.; Shiro, M.; Fujioka, H.; Maruyama, A.; Kita, Y. Asymmetric Dearomatizing Spirolactonization of Naphthols Catalyzed by Spirobiindane-Based Chiral Hypervalent Iodine Species. J. Am. Chem. Soc. 2013, 135, 4558-4566; (i) Uyanik, M.; Yasui, T.; Ishihara, K. Hydrogen Bonding and Alcohol Effects in Asymmetric Hypervalent Iodine Catalysis: Enantioselective Oxidative Dearomatization of Phenols. Angew. Chem. 2013, 125, 9385-9388; (j) Volp, K. A.; Harned, A. M. Chiral Aryl Iodide Catalysts for the Enantioselective Synthesis of ParaQuinols. Chem. Commun. 2013, 49, 3001-3003; (k) Uyanik, M.; Sasakura, N.; Mizuno, M.; Ishihara, K. Enantioselective Synthesis of Masked Benzoquinones Using Designer Chiral Hypervalent Organoiodine(III) Catalysis. ACS Catal. 2017, 7, 872-876; (1) Dohi, T.; Sasa, H.; Miyazaki, K.; Fujitake, M.; Takenaga, N.; Kita, Y. Chiral Atropisomeric 8,8'-Diiodobinaphthalene for Asymmetric Dearomatizing Spirolactonizations in Hypervalent Iodine Oxidations. J. Org. Chem. 2017, 82, 11954-11960; (m) Ogasawara, M.; Sasa, H.; Hu, H.; Amano, Y.; Nakajima, H.; Takenaga, N.; Nakajima, K.; Kita, Y.; Takahashi, T.; Dohi, T. Atropisomeric Chiral Diiododienes (Z,Z)-2,3-Di(1-iodoalkylidene)tetralins: Synthesis, Enantiomeric Resolution, and Application in Asymmetric Catalysis. Org. Lett. 2017, 19, 4102-4105; (n) Jain, N.; $\mathrm{Xu}, \mathrm{S}$.; Ciufolini, M. A. Asymmetric Oxidative Cycloetherification of Naphtholic Alcohols. Chem. Eur. J. 2017, 23, 4542-4546; (o) Hash- imoto, T.; Shimazaki, Y.; Omatsu, Y.; Maruoka, K. Indanol-Based Chiral Organoiodine Catalysts for Enantioselective Hydrative Dearomatization. Angew. Chem. Int. Ed. 2018, 57, 7200-7204; (p) Ding, Q.; He, H.; Cai, Q. Chiral Aryliodine-Catalyzed Asymmetric Oxidative C-N Bond Formation via Desymmetrization Strategy. Org. Lett. 2018, 20, 4554-4557.

(6) Zheng, H.; Sang, Y.; Houk, K. N.; Xue, X.-S.; Cheng, J.-P. Mechanism and Origins of Enantioselectivities in Spirobiindane-Based Hypervalent Iodine(III)-Induced Asymmetric Dearomatizing Spirolactonizations. J. Am. Chem. Soc. 2019, 141, 16046-16056.

(7) Harned, A. M. Concerning the Mechanism of Iodine(III)Mediated Oxidative Dearomatization of Phenols. Org. Biomol. Chem. 2018, 16, 2324-2329.

(8) Tang, T.; Harned, A. M. Experimental Evidence for the Formation of Cationic Intermediates during Iodine(III)-Mediated Oxidative Dearomatization of Phenols. Org. Biomol. Chem. 2018, 16, 82498252 .

(9) Ganji, B.; Ariafard, A. DFT Mechanistic Investigation into Phenol Dearomatization Mediated by an Iodine(III) Reagent. Org. Biomol. Chem. 2019, 17, 3521-3528.

(10) Wells, G.; Seaton, A.; Stevens, M. F. G. Structural Studies on Bioactive Compounds. 32. Oxidation of Tyrphostin Protein Tyrosine Kinase Inhibitors with Hypervalent Iodine Reagents. J. Med. Chem. 2000, 43, 1550-1562.

(11) The involvement of radicals in the mechanism of the iodine(III)-promoted dearomatization of phenols was proposed before, but this idea has not been examined further, see: Gates, B. D.; Dalidowicz, P.; Tebben, A.; Wang ; Swenton, J. S. J. Org. Chem. 1992, 57, $2135-2143$

(12) Litwinienko, G.; Ingold, K. U. Solvent Effects on the Rates and Mechanisms of Reaction of Phenols with Free Radicals. Acc. Chem. Res. 2007, 40, 222-230.

(13) (a) Mahoney, L. R. Antioxidants. Angew. Chem. Int. Ed. 1969, 8, 547-555; (b) Burton, G. W.; Ingold, K. U. Vitamin E: Application of the Principles of Physical Organic Chemistry to the Exploration of Its Structure and Function. Acc. Chem. Res. 1986, 19, 194-201; (c) Methods in Enzymology; Packer, L.; Glazer, A. N., Eds.; Academic Press, 1990; Vol. 186; (d) Foti, M. C. Antioxidant Properties of Phenols. J. Pharm. Pharmacol. 2007, 59, 1673-1685; (e) Gijsman, P. Polymer Stabilization. In Handbook of Environmental Degradation of Materials; Kutz, M., Ed.; William Andrew Publishing: Oxford, 2012; pp 673-714.

(14) (a) Stubbe, J.; van der Donk, W. A. Protein Radicals in Enzyme Catalysis. Chem. Rev. 1998, 98, 705-762; (b) Yamamura, S. Oxidation of Phenols. In PATAI'S Chemistry of Functional Groups; Rappoport, Z., Ed.; John Wiley \& Sons, Ltd.: 2009; (c) Blum, T. R.; Zhu, Y.; Nordeen, S. A.; Yoon, T. P. Photocatalytic Synthesis of Dihydrobenzofurans by Oxidative $[3+2]$ Cycloaddition of Phenols. Angew. Chem. Int. Ed. 2014, 53, 11056-11059; (d) Hopkinson, M. N.; GómezSuárez, A.; Teders, M.; Sahoo, B.; Glorius, F. Accelerated Discovery in Photocatalysis Using a Mechanism-Based Screening Method. Angew. Chem. Int. Ed. 2016, 55, 4361-4366.

(15) (a) Togo, H.; Katohgi, M. Synthetic Uses of Organohypervalent Iodine Compounds Through Radical Pathways. Synlett 2001, 565-0581; (b) Wang, L.; Liu, J. Synthetic Applications of Hypervalent Iodine(III) Reagents Enabled by Visible Light Photoredox Catalysis. Eur. J. Org. Chem. 2016, 1813-1824; (c) Budhwan, R.; Yadav, S.; Murarka, S. Late Stage Functionalization of Heterocycles Using Hypervalent Iodine(III) Reagents. Org. Biomol. Chem. 2019, 17, 6326-6341; (d) Wang, X.; Studer, A. Iodine(III) Reagents in Radical Chemistry. Acc. Chem. Res. 2017, 50, 1712-1724.

(16) (a) Kita, Y.; Tohma, H.; Hatanaka, K.; Takada, T.; Fujita, S.; Mitoh, S.; Sakurai, H.; Oka, S. Hypervalent Iodine-Induced Nucleophilic Substitution of Para-Substituted Phenol Ethers. Generation of Cation Radicals as Reactive Intermediates. J. Am. Chem. Soc. 1994, 116, 3684-3691; (b) Colomer, I.; Batchelor-McAuley, C.; Odell, B.; Donohoe, T. J.; Compton, R. G. Hydrogen Bonding to Hexafluoroisopropanol Controls the Oxidative Strength of Hypervalent Iodine Reagents. J. Am. Chem. Soc. 2016, 138, 8855-8861. 
(17) The EPR spectra measured in pure 1,4-dioxane and toluene (Figures S2 and S3) are qualitatively similar to this in Figure 4A, indicating that the formation of radicals from $\mathbf{1}$ and PIDA is not unique for the 1,4-dioxane/ $\mathrm{H}_{2} \mathrm{O}$ mixture.

(18) Maity, A.; Frey, B. L.; Hoskinson, N. D.; Powers, D. C. Electrocatalytic C-N Coupling via Anodically Generated Hypervalent Iodine Intermediates. J. Am. Chem. Soc. 2020, 142, 4990-4995.

(19) Theoretical predication of EPR spectra for iodine-containing radicals is troublesome, due to the relativistic effects present in heavy atoms.

(20) (a) Griller, D.; Ingold, K. U. Free-Radical Clocks. Acc. Chem. Res. 1980, 13, 317-323; (b) Newcomb, M. Competition Methods and Scales for Alkyl Radical Reaction Kinetics. Tetrahedron 1993, 49, 1151-1176.

(21) While the cyclization of a primary 5-hexenyl radical has a rate constant of $2.3 \cdot 10^{5} \mathrm{~s}^{-1}$ at $25^{\circ} \mathrm{C}$ (see, Chatgilialoglu, C.; Ingold, K. U.; Scaiano, J. C Rate Constants and Arrhenius Parameters for the Reactions of Primary, Secondary, and Tertiary Alkyl Radicals with Tri- $n$ butyltin Hydride. J. Am. Chem. Soc. 1981, 103, 7739-7742), for the corresponding benzylic 1-phenyl-5-hexenyl radical, the cyclization rate constant is already as low as $0.14 \mathrm{~s}^{-1}$ (see, Franz, J. A.; Barrows, R. D.; Camaioni, D. M. Arrhenius Parameters for Rearrangements of the Neophyl, 1-Indanylmethyl, 2-Allylbenzyl, and 2-(2-Vinylphenyl)ethyl Radicals Relative to Hydrogen Abstraction from Tributylstannane. $J$. Am. Chem. Soc. 1984, 106, 3964-3967). Aryloxyl radical 3 is expected be even more stable than the benzylic radical, thus the rate at which it cyclizes should be still lower.

(22) Typical rate constants for the opening of cyclopropylcarbinyl radical are in the range of $10^{7}-10^{9} \mathrm{~s}^{-1}$ at $25^{\circ} \mathrm{C}$, see: Bowry, V. W.; Lusztyk, J.; Ingold, K. U. Calibration of a New Horologery of Fast Radical Clocks. Ring-Opening Rates for Ring- and $\alpha$-Alkyl-Substituted Cyclopropylcarbinyl Radicals and for the Bicyclo[2.1.0]pent-2-yl Radical. J. Am. Chem. Soc. 1991, 113, 5687-5698.

(23) For examples of acetamidations of radicals by the reaction with MeCN, see: (a) Hammerich O.; Parker, V. D. Reaction of the Anthracene Cation Radical with Acetonitrile. A Novel Anodic Acetamidation. J. Chem. Soc., Chem. Commun. 1974, 245-246. (b) Engel, P. S.; Lee, W. K.; Marschke, G. E.; Shine, H. J. The Reactions of 1-Adamantyl Radicals with Acetonitrile and Their Bearing on the Oxidative Decomposition of 1,1'-Azoadamantane. J. Org. Chem. 1987, 52, 28132817.

(24) For a recent study on the sensitivity of mechanistically different radical reactions, see: Pitzer, L.; Schäfers F.; Glorius, F. Rapid
Assessment of the Reaction-Condition-Based Sensitivity of Chemical Transformations. Angew. Chem. Int. Ed. 2019, 58, 8572-8576.

(25) Bowry, V. W.; Ingold, K. U. Kinetics of Nitroxide Radical Trapping. 2. Structural Effects. J. Am. Chem. Soc. 1992, 114, 4992 4996.

(26) Schardt, B. C.; Hill, C. L. Preparation of Iodobenzene Dimethoxide. A New Synthesis of $\left[{ }^{18} \mathrm{O}\right]$ Iodosylbenzene and a Reexamination of Its Infrared Spectrum. Inorg. Chem. 1983, 22, 1563-1565.

(27) Richter, H. W.; Cherry, B. R.; Zook, T. D.; Koser, G. F. Characterization of Species Present in Aqueous Solutions of [Hydroxy(mesyloxy)iodo]benzene and [Hydroxy(tosyloxy)iodo]benzene. J. Am. Chem. Soc. 1997, 119, 9614-9623.

(28) Silva, L. F.; Vasconcelos, R. S.; Lopes, N. P. Application of High-Resolution Electrospray Mass Spectrometry for the Elucidation of the Disproportionation Reaction of Iodobenzene Diacetate. Int. J. Mass Spectrom. 2008, 276, 24-30.

(29) A slight shift toward a less negative potential may be due to a hydrogen bonding between PIDA and H2O, similarly but to a lower extent as has been observed for the binding between PIDA HFIP (see Ref. $16 \mathrm{~b}$ for details)

(30) The oxidative dearomitizing acetoxylation of phenols with PIDA requires heating in neat acetic acid and it is considerably slower than the hydroxylation. For example, see: Novak, M.; Glover, S. A. Generation and Trapping of the 4-Biphenylyloxenium Ion by Water and Azide: Comparisons with the 4-Biphenylylnitrenium Ion. J. Am. Chem. Soc. 2004, 126, 7748-7749.

(31) The equilibrium isotope effect for the conversion of PIDA to $\mathbf{8}$ is expected to be negligible, as the fractionation factors for the distribution of deuterium between different $\mathrm{OH}$ groups are close to 1 , see: Gold, V. Protolytic Processes in $\mathrm{H}_{2} \mathrm{O}-\mathrm{D}_{2} \mathrm{O}$ Mixtures. Adv. Phys. Org. Chem. 1969, 7, 259-331.

(32) The considerably large quantity of the presumed iodanyl(II) radical detected by the EPR (Figure 4 ; $\sim 1$ :1 ratio vs. 3 ) is in a contradiction with the kinetic data. Namely, the accumulation of this radical implies that its fragmentation and the subsequent reaction with phenol $\mathbf{1}$ have a comparable rate to that for the reaction between radical $\mathbf{3}$ and 8. This would in turn result in the appearance of the concentration of $\mathbf{1}$ in the rate law, which is not the case. However, the kinetics was measured in MeCN/H2O, while the EPR spectra was registered in 1,4-dioxane/H2O, wherein the relative rates of the mechanistic steps may be different. 